\title{
Metformin decreases the incidence of ovarian hyperstimulation syndrome: an experimental study
}

Evelin M Elia ${ }^{1}$, Ramiro Quintana ${ }^{2}$, Carlos Carrere², María V Bazzano ${ }^{3}$, Gastón Rey-Valzacchi ${ }^{2}$, Dante A Paz ${ }^{1,3^{*}}$ and María C Pustovrh ${ }^{1,4}$

\begin{abstract}
Background: In assisted reproduction cycles, gonadotropins are administered to obtain a greater number of oocytes. A majority of patients do not have an adverse response; however, approximately 3-6\% develop ovarian hyperstimulation syndrome (OHSS). Metformin reduces the risk of OHSS but little is known about the possible effects and mechanisms of action involved.

Objective: To evaluate whether metformin attenuates some of the ovarian adverse effects caused by OHSS and to study the mechanisms involved.

Material and methods: A rat OHSS model was used to investigate the effects of metformin administration. Ovarian histology and follicle counting were performed in ovarian sections stained with Masson trichrome. Vascular permeability was measured by the release of intravenously injected Evans Blue dye (EB). VEGF levels were measured by commercially immunosorbent assay kit. COX-2 protein expression was evaluated by western blot and NOS levels were analyses by immunohistochemistry.

Results: Animals of the OHSS group showed similar physiopathology characteristics to the human syndrome: increased body weight, elevated progesterone and estradiol levels $(P<0.001)$, increased number of corpora lutea $(P<0.001)$, higher ovarian VEGF levels and vascular permeability $(P<0.001$ and $P<0.01)$; and treatment with metformin prevented this effect (OHSS+M group; $P<0.05)$. The vasoactive factors: COX-2 and NOS were increased in the ovaries of the OHSS group $(P<0.05$ and $P<0.01)$ and metformin normalized their expression $(P<0.05)$; suggesting that metformin has a role preventing the increased in vascular permeability caused by the syndrome.

Conclusion: Metformin has a beneficial effect preventing OHSS by reducing the increase in: body weight, circulating progesterone and estradiol and vascular permeability. These effects of metformin are mediated by inhibiting the increased of the vasoactive molecules: VEGF, COX-2 and partially NOS. Molecules that are increased in OHSS and are responsible for a variety of the symptoms related to OHSS.
\end{abstract}

\footnotetext{
* Correspondence: danteagustin.paz@gmail.com

${ }^{1}$ Laboratorio de Biología del Desarrollo, Facultad de Ciencias Exactas y

Naturales, Instituto de Fisiología, Biología Molecular y Neurociencias

(IFIBYNE-CONICET-UBA), Pabellón 2, 4 C1428EHA Cdad Universitaria, Buenos

Aires, Argentina

${ }^{3}$ Departamento de Biodiversidad y Biología Experimental, Facultad de

Ciencias Exactas y Naturales, Universidad de Buenos Aires, Pabellón 2, Cdad,

Universitaria, Buenos Aires, Argentina

Full list of author information is available at the end of the article
} 


\section{Introduction}

In assisted reproduction cycles, gonadotropins are administered to obtain a greater number of oocytes. A majority of patients do not have an adverse response; however, approximately 3-6\% develop ovarian hyperstimulation syndrome (OHSS), which is characterized by a variety of manifestations including ascites, pleural hemorrhage, hemoconcentration and oliguria. In the severe OHSS, a form of thromboembolism can occur, and without medical care, it may lead to death $[1,2]$.

The main characteristic of these manifestations is an increase in vascular permeability caused by the release of hCG mediators; however, this mechanism is not fully understood. Among the wide variety of angiogenic and vasoactive molecules, vascular endothelial growth factor (VEGF) plays a preponderant role. The production of VEGF in endothelial cells is increased by treatment with hCG, and in turn, the growth factor increases vascular permeability [1]. In the ovary, VEGF is produced in teca and granulose cells. There have been reports showing a relationship between serum VEGF levels and the administration of hCG, suggesting that it can be used as an OHSS predictor [2-4]. Moreover, Gomez et al. has suggested that targeting VEGF and its receptor was an effective preventive approach to treat the syndrome $[5,6]$. In the mouse skin, Fujii et al. have described that the vascular permeability induced by VEGF is mediated by the local production of nitric oxide $(\mathrm{NO})$ and arachidonic acid metabolites, which are mainly produced by NO synthase (NOS) and cyclooxygenase type 2 (COX-2), respectively [7].

We have previously demonstrated that a beneficial effect of meloxicam (a COX-2 inhibitor) in OHSS is the reduction of ovarian weight and VEGF expression in a rat model of OHSS (Quintana et al., 2008). However, the administration of meloxicam during in vitro fertilization procedures is not recommended because it blocks ovulation by inhibiting the breakdown of mature ovarian follicles $[8,9]$.

Metformin ( $N, N$-dimethylbiguanide) is one of the most common drugs used for the treatment of type 2 diabetes. Among the various actions of metformin are its effect activating the adenosine 3'5'-monophosphate (AMP) dependent kinase alpha (AMPK-a) pathway, decreasing the glucose production, increasing fatty acid oxidation and promoting the uptake of glucose in cells [10-13]. In polycystic ovary syndrome (PCOS), metformin decreases androgen levels, improves the frequency of ovulation and menstrual cycles, normalizes uterine homeostasis and prevents miscarriages [14-17]. Metformin administration also increases the embryo quality, the clinical pregnancy rate as well as the implantation rate [18], and it is important to highlight that the mechanism of action of metformin involves the modulation of NOS and COX-2 expression in the ovary and the uterus [19-21].

In contrast, it has been demonstrated that PCOS patients undergoing fertility treatment who receive gonadotrophins have an increased risk for OHSS. Whereas, when those women were treated with metformin, the risk of OHSS was reduced [22]. However, little is known about the possible effects and mechanisms by which metformin reduces the risk of OHSS.

In view of these findings, metformin appears to be an alternative treatment for the prevention of OHSS; however, there are no reports that take in consideration the mechanisms by which metformin regulates ovarian physiology in OHSS. Therefore, the purpose of this study is to evaluate whether metformin attenuates some of the ovarian adverse effects in OHSS in an animal model and to study the mechanisms involved.

\section{Materials and methods Study design}

Immature female Wistar rats were obtained from Bioterio Central, Facultad de Ciencias Exactas y Naturales, UBA. All research animals were treated in compliance with the guidelines for the care and use of animals approved by our institutions in accordance with the principles of laboratory animal care (NIH Guide for the Care and Use of Laboratory Animals, Institute of Laboratory Animal Resources, National Research Council, Washington, D.C.). Rats were fed with a standard diet, allowed free access to water, and had a 12-hour light cycle (lights-on 7AM to 7PM).

Thirty female rats (weight: $44-50 \mathrm{~g}$ ) were divided into three groups: (1) the control group $(n=10)$, which received $10 \mathrm{IU}$ of pregnant mare serum gonadotropin (PMSG; Sigma Chemical Co) on the 39th day and $10 \mathrm{IU}$ of hCG (Sigma) 48 hours later (day 41) to mimic routine ovarian stimulation; (2) the OSSH group $(n=10)$, which received 50 IU of PMSG daily from days 37 to 40 and 30 IU hCG on day 41 to induce OHSS; (3) the OHSS+ MET group $(\mathrm{n}=10)$, which underwent the same hormonal stimulation protocol as the OHSS group in addition to treatment with metformin (Boehringer, Buenos Aires, Argentina) (50 mg/kg body weight) for 20 consecutive from days 22 to 41 . The OHSS animal model has been first described by Ujioka et al. [23] and later used by other authors including our group [4,24-26], showing that this model shows the main characteristics of the human syndrome.

All hormones were intraperitoneally administered, while metformin was administered orally. The following two series of experiments were performed $48 \mathrm{~h}$ after the hCG injections. In the first series, both ovaries from five rats in each group were weighed and then homogenized for immunoblot analysis and VEGF level measurement. The blood was used for hormone assays and VEGF level 
determination. In the second series of experiments, one ovary from five rats in each group was used to measure ovarian vascular permeability with Evans Blue (EB), and the other was used for immunohistochemistry and follicular counting.

\section{Evaluation of vascular permeability}

Vascular permeability was measured by monitoring the release of intravenously injected Evans Blue dye (EB) into the peritoneal fluid and ovarian tissue as previously described [24,27]. Briefly, 48 hours after hCG administration, $5 \mathrm{mM}$ EB dye was diluted in distilled water and $0.2 \mathrm{ml}$ was intravenously (i.v.) injected with an insulin injector through the tail vein. After a 30-min waiting period, all rats were weighed and intramuscularly administered 40/4 mg/kg ketamine (Ketafine; Brouwer, Argentina) / xilacine (Xylacine; Alfasan Woerden-Holland, Holland). Then, the peritoneal cavity was filled with $5 \mathrm{ml} 0.9 \% \mathrm{NaCl}$ solution and massaged for 30 seconds, and subsequently, the fluid was gently extracted from the abdominal cavity to prevent tissue or vessel damage. Protein interference was avoided by recovering the peritoneal fluid in tubes containing $0.05 \mathrm{ml} 0.1 \mathrm{~N} \mathrm{NaOH}$. Fluid was clarified by centrifugation at $900 \times g$ for $12 \mathrm{~min}$, and then it was used to determine the EB concentration in the recovered fluid. Then, euthanasia was performed, and the ovaries were removed. One ovary was removed and fixed in \% (w/v) formaldehyde, and the other ovary was incubated in $2 \mathrm{ml}$ of formamide for $24 \mathrm{hsh}$ at $37^{\circ} \mathrm{C}$.

The EB concentration in the formamide extract and in peritoneal fluid was measured as a function of light absorption at $600 \mathrm{~nm}$, which was determined using a spectrophotometer. The EB concentration was expressed as micrograms per $\mathrm{mL}$ of the peritoneal fluid, and the ovarian EB content was expressed as nanograms per milligram tissue wet weight.

\section{Hormone assays}

Serum estradiol levels were measured using an electrochemiluminescene immunoassay (ECLIA) according to the manufacturer's instructions (Elecsys analyzer Roche Diagnostics), and serum progesterone levels were measured by an immunochemiluminescence assay (ICMA). All samples were measured at the same time to minimize errors. Results are expressed as nanograms per $\mathrm{dL}$ serum for $\mathrm{P}_{4}$, and for $E_{2}$, they are expressed as picograms per serum milliliter.

\section{Immunohistochemistry}

Fixed ovarian samples were dehydrated and embedded in paraffin. Six-micron sections were mounted on gelatin-coated glass slides, deparaffinized in xylene, hydrated through a series of graded alcohols and washed in phosphate-buffered saline (PBS). The tissue sections were treated with $3 \%$ hydrogen peroxide $\left(\mathrm{H}_{2} \mathrm{O}_{2}\right)$ to quench endogenous peroxidase activity. Nonspecific binding sites were blocked by treating the tissues with $5 \%(\mathrm{w} / \mathrm{v})$ non-fat milk at room temperature for $30 \mathrm{~min}$ and subsequently incubated with primary antibodies for 24 hours at $4^{\circ} \mathrm{C}$ in a dark, moist chamber. We used a rabbit anti-NOS (ab-15203, Abcam, Cambridge, Mass, USA) antibody. After incubation with primary antibody, the sections were washed with PBS and treated with the appropriate biotinylated antibody (Vector Laboratories, Burlingame, United Kingdom) followed by an avidinhorseradish peroxidase-biotin complex (Vectastatin Elite ABC kit; Vector Lab, Burlingame, Calif, USA). The color reaction was visualized by exposure with the 30 , 30-diaminobenzidine tetrahydrochloride DAB staining kit (Dako Cytomation, Carpinteria, CA, USA). Negative control sections were performed by omitting primary antibody. After color development, sections were counterstained with Mayer's hematoxylin solution (Dako). Images from a standard light microscope were acquired with the Cool-SNAP-Pro Color camera system and analyzed with Image ProPlus 6.2 software (Media Cybernetics, Bethesda, MD).

\section{Ovarian histology and follicle counting}

Ovarian tissue sections were stained with Masson trichrome stain and used to show the smooth muscle according to standard protocols and analyzed under a Zeiss Axiophot light microscope. Six-micron sections were mounted at $50 \mu \mathrm{m}$ intervals onto microscope slides to prevent counting the same structure twice, according to the method described by Woodruff et al. [28]. Follicles were classified into three types: Preantral (PFs), antral (AFs) and preovulatory (POs). In the PFs group we gathered all the follicles that had no antrum, including primordial, primaries and preantral follicles strictly speaking. Primordial follicles were characterized as oocytes surrounded by a single layer of flattened granulosa cells. Primary follicles were characterized as oocytes surrounded by a single layer of cuboidal granulosa cells. Preantral follicles were characterized as oocytes surrounded by two or more layers of cuboidal granulosa cells with no visible antrum.

AFs were classified according to the presence of a small antrum and POs according to the presence of a big central antrum showing an eccentric oocyte. In addition, the number of corpora lutea (CL) was counted in each section analyzed. To assess the ovulation rate in the ovarian tissue, the number of corpora lutea was determined in the same sections as the other types of follicles. The abundance of each type of follicle was normalized by the total ovarian area in the section as reported previously $[29,30]$. The ovary area was measured with Image J (version 1.42q) and expressed per $10 \mathrm{~mm}^{2}$. 


\section{Ovarian homogenates}

Ten ovaries from each group were lysed for $20 \mathrm{~min}$ at $4^{\circ} \mathrm{C}$ in lysis buffer $(20 \mathrm{mM}$ Tris- $\mathrm{HCl}, \mathrm{pH}=8.0,137 \mathrm{mM} \mathrm{NaCl}$, $1 \%$ Nonidet P-40 and 10\% glycerol) supplemented with 1 $\mathrm{X}$ protease inhibitors cocktail (Sigma). The lysate was centrifuged at $4^{\circ} \mathrm{C}$ for $10 \mathrm{~min}$ at $10000 \times g$, and the pellet was discarded. Protein concentrations in the supernatant were measured by Bradford assay (Bio-Rad, Hercules, CA, USA).

\section{Determination of serum on ovarian VEGF levels}

VEGF-A concentration was measured by commercially available Sandwich Enzyme-Linked Immunosorbent assay kit for rat VEGF (R \& D System, Minneapolis, USA) using serum and ovarian homogenates. Assay was performed according to the manufacturer's instruction. The detection sensitivity range of the kit was $30-2000 \mathrm{pgml}^{-1}$ and showed no cross-reactivity with a series of soluble immunoactive molecules with a good reproducibility. The coefficient of variation was less than $9.5 \%$. Results are expressed as $\mathrm{pg} / \mathrm{mg}$ of tissue wet weight or $\mathrm{pg} / \mathrm{mL}$ peritoneal fluid.

\section{Western blot}

After boiling for $5 \mathrm{~min}$ the ovarian lysates, $90 \mu \mathrm{g}$ of protein from each sample was applied to an SDS-polyacrylamide gel (10\%) and electrophoresis was performed at $100 \mathrm{~V}$ for $1.5 \mathrm{~h}$. The separated proteins were transferred onto PDVF membranes in transfer buffer (20\% methanol, vol/vol; $0.19 \mathrm{M}$ glycine; $0.025 \mathrm{M}$ Tris-Base, $\mathrm{pH}=8.3$ ) for $1 \mathrm{~h}$ at $4^{\circ} \mathrm{C}$. Blots were blocked for $1.5 \mathrm{~h}$ in TBS $(4 \mathrm{mM}$ Tris- $\mathrm{HCl}$, $\mathrm{pH}=7.5,100 \mathrm{mM} \mathrm{NaCl}$ ) containing bovine serum albumin $(0.1 \%)$ at room temperature. Rabbit polyclonal antiCOX2 (1:500, overnight). Santa Cruz Biotechnology Inc., USA) and Glyceraldehyde-3-PDH (GADPH) (Millipore, USA) were used as primary antibodies. Rainbow-colored protein mass markers $(14.3-200 \mathrm{kDa}$, Bio-Rad) were applied to determine the bands of COX2 $(72 \mathrm{kDa})$ and GADPH $(38 \mathrm{kDa})$. Protein bands were visualized by incubating the blots with biotin-conjugated secondary antirabbit IgG (1:2000, $1 \mathrm{~h}$ ) followed by streptavidin-peroxidase complex and diaminobenzidine solution. Consistency of protein loading was evaluated by staining the membranes with Ponceau-S and relative to the GADPH protein levels. The intensities (area $\times$ density) of the individual bands on western blots were quantified by densitometry (Model GS-700, Imaging Densitometer, Bio-Rad). The experiment was independently repeated three times. Results are expressed in arbitrary units.

\section{Statistical analysis}

Results are expressed as mean \pm SEM. Comparisons between groups were performed using either one-way ANOVA in conjunction with Tukey's test or Student's $t$-test, where appropriate. The statistical level of significance was defined as $P<0.05$.

\section{Results}

Measurement of body, ovarian and uterine weight and serum hormone levels

The effects of hyperstimulation and metformin on the body, ovarian and uterine weight and serum estradiol and progesterone are summarized in Table 1 . Body weights were increased in hyperstimulated animals (OHSS group) with respect to control rats $(\mathrm{p}<0.001)$, and pretreatment with metformin (OHSS+MET) prevented this effect. The ovarian and uterine weights of the OHSS rats were greater than the control rats $(\mathrm{p}<0.001$ and 0.05 , respectively), while treatment with metformin did not modify these parameters.

The progesterone and estradiol levels were greater in OHSS rats compared with control animals $(\mathrm{p}<0.001)$, and metformin prevented the increase in estradiol levels.

\section{Ovarian morphology}

To study the effects caused by metformin on ovarian morphology in the OHSS rat model, ovarian tissue sections were stained to determine the number of follicles in follicle stages (Figure 1). In the OHSS group, the number of preantral, antral and preovulatory follicles were significantly lower than that in the control group, while the number of CLs were higher in the OHSS group. Metformin significantly increased the number of preantral and antral follicles in treated compared with

\section{Table 1 Body weight and endocrine characteristics of control and hyperstimulated animals}

\begin{tabular}{cccc}
\hline & Control & OHSS & OHSS + M \\
\hline Body weight $(\mathrm{g})$ & $149,2 \pm 1,0$ & $167,8 \pm 3,1^{* * *}$ & $156,2 \pm 3,9 \#$ \\
Ovarian weight $(\mathrm{mg})$ & $63,2 \pm 2,4$ & $224,0 \pm 13,1^{* * *}$ & $233,3 \pm 15,4^{* * *}$ \\
Uterine weight $(\mathrm{mg})$ & $231,6 \pm 15,3$ & $322,6 \pm 21,9^{*}$ & $362,5 \pm 29,9^{* *}$ \\
Progesterone $(\mathrm{ng} / \mathrm{dL})$ & $188,7 \pm 26,3$ & $1035 \pm 122,9^{* * *}$ & $751,1 \pm 115,7^{* *}$ \\
Estradiol $(\mathrm{pg} / \mathrm{mL})$ & $36,3 \pm 0,7$ & $166,3 \pm 23,0^{* *}$ & $98,5 \pm 22,3 \#$ \\
$n$ & 10 & 10 & 10 \\
\hline
\end{tabular}

Values are expressed as mean \pm S.E.M and the $P$ values were determined by one way ANOVA, followed by Tukey's test. ${ }^{*} \mathrm{P}<0,05,{ }^{* *} \mathrm{P}<0,01$ and ${ }^{* * *} \mathrm{P}<0,001$ respect to control group; ${ }^{\#} \mathrm{P}<0,05$ respect to the $\mathrm{OSSH}$ group. 


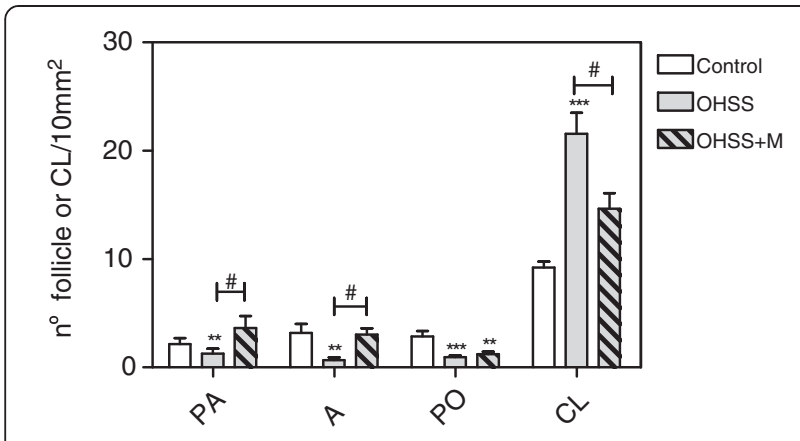

Figure 1 Effect of the treatment with Metformin on the ovarian morphology in an OHSS rat model. This is a quantitative morphometric analysis of the ovarian sections after Masson trichrome staining. Follicles were classified according to the stage of development indicated in materials and methods. Values are expressed as the number of follicles per $10 \mathrm{~mm}^{2}$. Data represent the mean \pm S.E.M for 10 ovaries from different animals with the same treatment, and each value represents the mean of 10 sections from the same ovary. ${ }^{* *} P<0.01$ and ${ }^{* * *} P<0.001$ respect to the control group; ${ }^{~} \mathrm{P}<0.05$ between the pointed groups.

the untreated OHSS group. Moreover, treatment with metformin normalized the number of CLs.

\section{Effects of OHSS and metformin on vascular permeability}

We were interested in evaluating the effects of treatment on vascular permeability because this is the main characteristic of the syndrome, and it is unknown whether metformin is able to prevent the increase in the capillary permeability. In our results, the ovarian EB content was significantly higher in hyperstimulated rats than control animals $(\mathrm{p}<0.01)$, indicating a significant increase in vascular permeability in this group; this effect was partially prevented by pre-treatment with metformin (OHSS vs. OHSS+MET, $\mathrm{p}<0.05$ ) (Figure 2). The same effect was

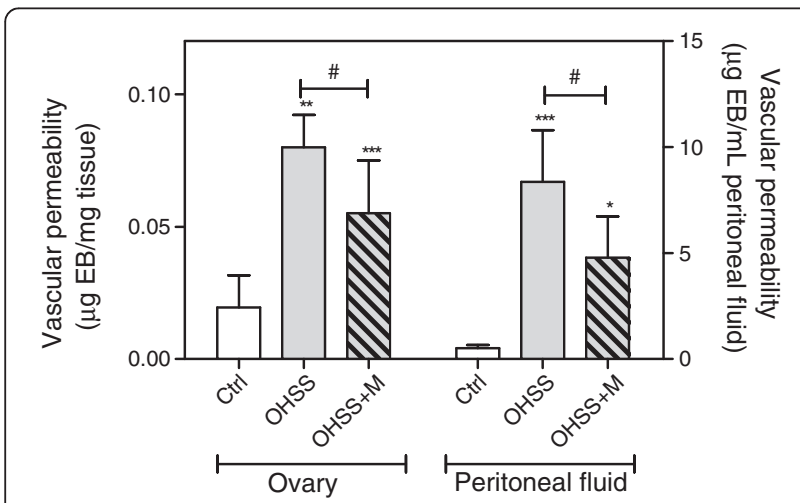

Figure 2 Vascular permeability measured as concentration of Evans Blue (EB) in ovaries homogenates and in peritoneal fluid. Each bar represents the mean \pm S.E.M and the $P$ values were determined by one way ANOVA, followed by Tukey's test. ${ }^{*} P<0.05$, ${ }^{*} \mathrm{P}<0.01$ and ${ }^{* *} \mathrm{P}<0.001$ respect to the control group; ${ }^{*} \mathrm{P}<0.05$ between the pointed groups. observed when we analyzed the peritoneal fluid EB content, where we found an increase in peritoneal fluid $E B$ content in hyperstimulated rats $(\mathrm{p}<0.001)$ that was partially prevented by pretreatment with metformin (OHSS vs. OHSS+MET, $\mathrm{p}<0.05$ ).

\section{Effect of OHSS and metformin on VEGF levels}

Because VEGF is the main factor involved in the pathology of OHSS, the level of this glycoprotein was measured in peripheral serum and the ovaries.

The ovarian VEGF concentration was significantly increased in the OHSS group with respect to the control group $(\mathrm{p}<0.001)$, and metformin partially reduced the VEGF concentration in treated compared with untreated OHSS rats (OHSS vs. OHSS+MET, $\mathrm{p}<0.05)$.

The serum VEGF concentration measured in OHSS rats showed an important increased in comparison with controls $(\mathrm{p}<0.001)$, but metformin administration did not show significant changes in this parameter (Figure 3).

\section{Ovarian cyclooxygenase protein expression}

COX-2 is another important angiogenic factor that acts through VEGF that is one of the most important proteins involved in ovulation. Thus, because we are inducing ovulation and found that the VEGF levels are altered after treatment, we decided to evaluate the ovarian COX-2 protein expression. We found an increase in COX-2 ovarian levels in OHSS rats $(\mathrm{p}<0.05)$ that was prevented when the animals received pretreatment with metformin (OHSS vs. OHSS+MET, $\mathrm{p}<0.05)$ (Figure 4).

\section{NOS protein localization}

The results of immunohistochemical analysis revealed moderate NOS staining in theca,granulose cells and oocytes from developed follicles in all groups analyzed.

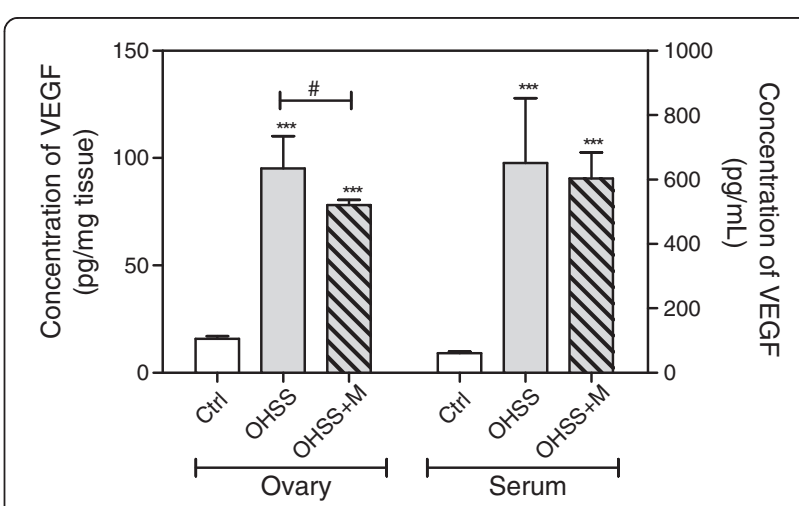

Figure 3 Concentration of the vascular endotelial growth factor (VEGF) in ovaries homogenates and in serum. Each bar represents the mean \pm S.E.M and the $P$ values were determined by one way ANOVA, followed by Tukey's test. ${ }^{* * *} P<0.001$ respect to the control group and \# $\mathrm{P}<0.05$ between the pointed groups. 


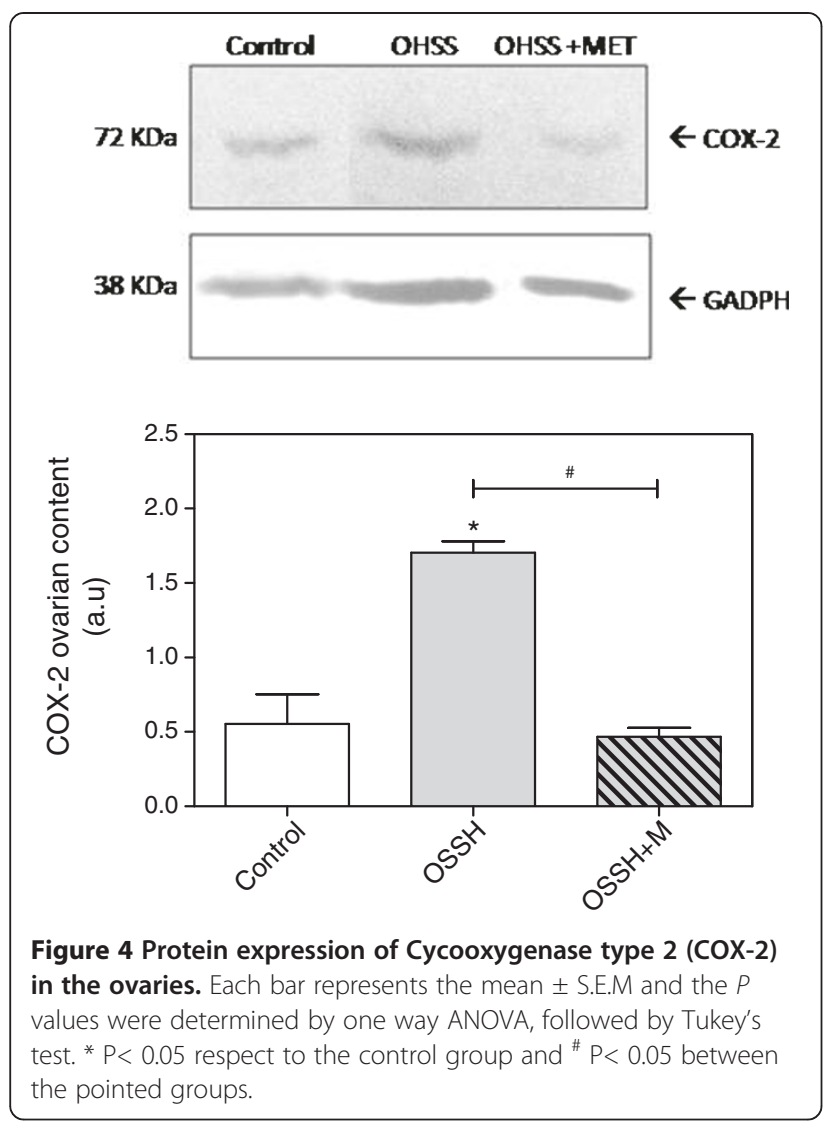

Ovaries from the OHSS group showed intense NOS immunoreactivity in the corpus luteum $(\mathrm{CL})$ when compared with CLs from the control group $(\mathrm{p}<0.01)$. In the OHSS+MET treatment group, NOS immunoreactivity was diminished in CLs when compared with those in the OHSS group $(\mathrm{p}<0.0001)$ (Figure 5$)$, suggesting that metformin affects NOS protein expression.

\section{Discussion}

Preventing OHSS remains a challenge for in vitro fertilization. Several strategies have been proposed for preventing the development of OHSS [31-38] as well as some drugs, such as oral contraceptives, leuprolide acetate, metformin, dexamethasone, low-dose aspirin and dopamine agonists. These drugs have been proven to be safe for other uses and are highly effective adjuncts for ovarian stimulation in "orphan" indications [39]. In particular, metformin administration has been confirmed to be a safe and effective strategy for reducing the incidence of OHSS [37]. Recently, it has been clinically demonstrated that it has been specified from a clinical point of view that metformin administration decreases the risk of moderate/severe OHSS by $80 \%$ and the risk of hospitalization by $75 \%$ [22]. Furthermore, patients with PCOS who are subfertile receive gonadotrophins while being treated with metformin to reduce the risk of
OHSS [40]. However, at present,metformin specific effects and mechanisms of action are still unknown.

In the results of this study, we found an increase in the number of CLs in the OHSS group showing an increase in the induced ovulation rate (Figure 1). This effect was found concomitantly with a reduction in the number of preantral, antral and preovulatory follicles, suggesting that hormonal administration induced ovulation without inducing early follicular development. In addition, treatment with metformin prevented the effects of hormonal administration because the number of CLs was normalized in the OHSS $+\mathrm{M}$ group, indicating that metformin acts by decreasing the ovulation rate. The fact that metformin normalized the ovulation rate and number of preantral and antral follicles suggests that metformin was capable of affecting early folliculogenesis and ovulation. This result is in concordance with the that described by De Leo [41] who found a reduction in the number of follicles $>15 \mathrm{~mm}$ in diameter in patients who received metformin treatment before the induction of ovulation. This finding indicates a lower incidence of ovarian overstimulation after metformin administration and supports the hypothesis that insulin plays a role in the endocrine and paracrine control of the ovaries [41].

Research suggests that VEGF is responsible for the increased vascular permeability leading to the extravasation of protein-rich fluid and subsequent OHSS progression $[42,43]$. In addition, high levels of VEGF have been detected in serum and follicular fluids from women with severe OHSS [44]. Here, we found increased VEGF levels in the ovaries and serum from rats with induced OHSS. Moreover, in this OHSS group, we detected one of the main characteristics of the syndrome: increased vascular permeability, which was demonstrated by the increased level of Evans Blue dye detected in different organs. In our results, this increased permeability was reduced with the metformin treatment (Figure 2). The increase in vascular permeability in the OHSS animals may be caused by the high levels of VEGF observed in this group as previously described [45,46]; however, further experiments are needed to clarify this point. Furthermore, it has been described in another system that metformin prevented the increased vascular permeability [47]. The fact that metformin prevented the increase in vascular permeability and the levels of VEGF (Figure 3) suggests that the mechanism by which metformin normalizes the vascular permeability may be through VEGF modulation.

In addition to VEGF, cyclooxygenase 2 (COX-2) has been described as an angiogenic factor in other systems $[48,49]$. COX-2 is a key enzyme in the conversion of arachidonic acid to prostaglandins and other eicosanoids. COX-2 is induced by a variety of factors, including cytokines, growth factors, and tumor promoters, and it is upregulated in many cancers and has been associated with 


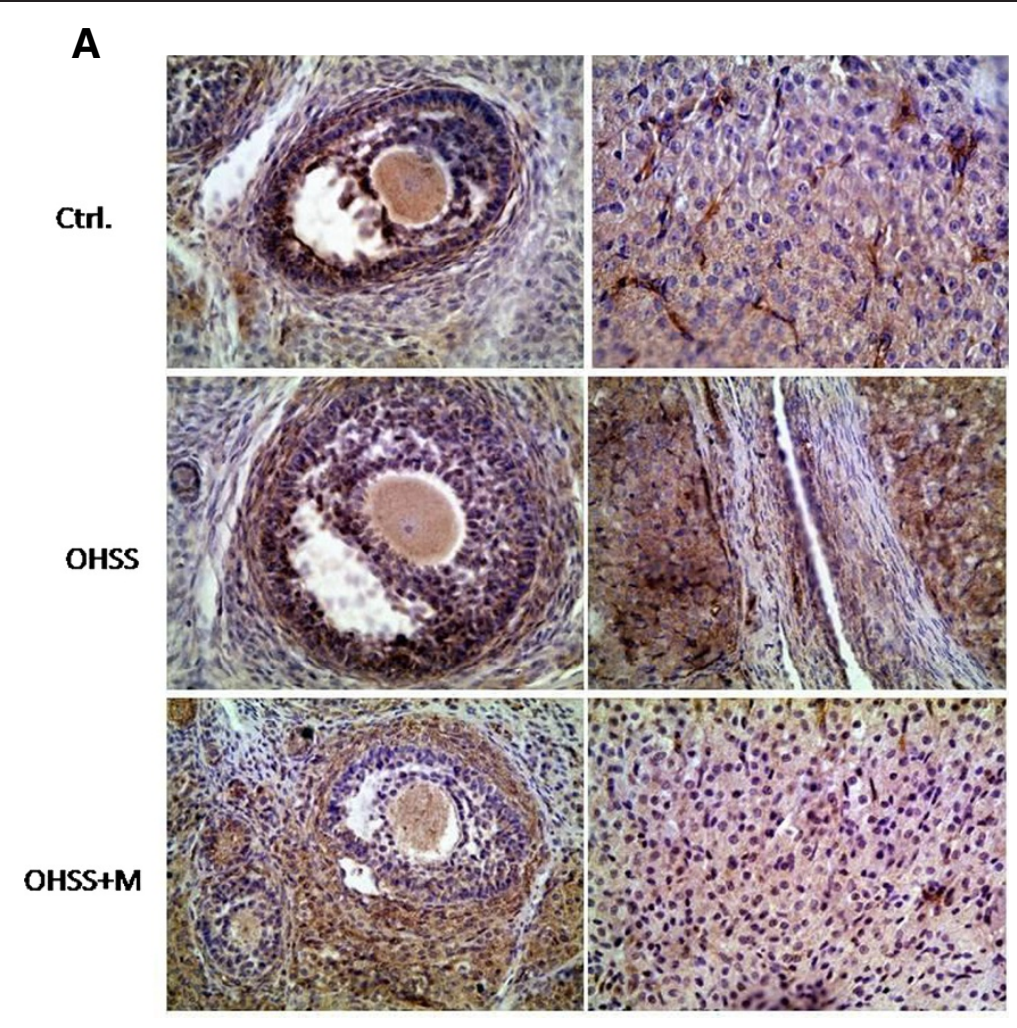

B

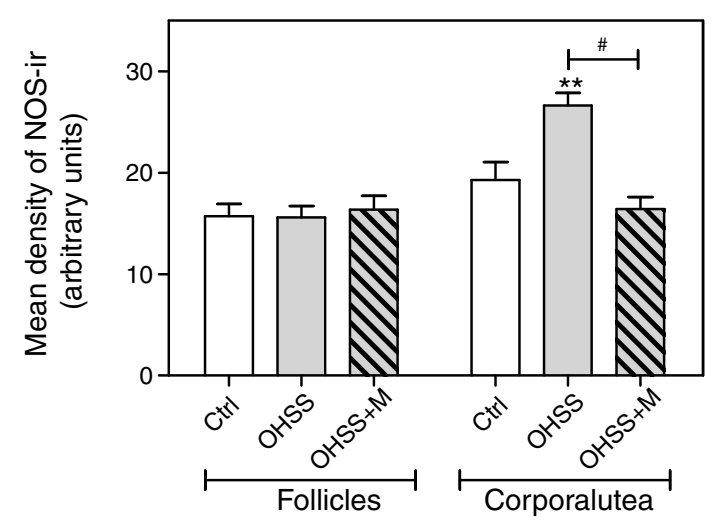

Figure 5 NOS immunoreactivity in control and treated rat ovaries. (A) Representative ovarian sections showing the immunolocalization of NOS from: upper panel: a control rat; middle panel: a OSSH rat; and lower panel: a OHSS+MET rat. A, C and E shows developed follicles ( $\times 100)$ while B, D and $F(\times 100)$ shows corpora lutea. (B) Densitometric analyses of NOS immunoreactivity in the rat ovaries. Each bar represents the mean \pm S.E.M and the Pvalues were determined by one way ANOVA, followed by Tukey's test. ${ }^{* *} P<0.01$ respect to the control group and \#P< 0.0001 between the pointed groups.

increased VEGF production and angiogenesis [50]. Moreover, the vascular permeability in mouse skin induced by VEGF, was mediated by modulation of NOS and COX-2 [7]. Although the importance of COX-2 in the ovulatory process has been documented, the exact functions of this prostaglandin in human ovaries, fertilization, and implantation are not completely understood [43].

In our results, we found an increase in the ovarian COX-2 expression in the OHSS group concomitantly with an increase in ovarian NOS levels. Our findings agree with previous reports that showed an increase in ovarian COX-2 expression in a mild OHSS condition [4] and suggest that, in our model, VEGF may be acting through COX-2 and NOS in the ovary.

In contrast, we found that metformin restored vascular permeability and normalized the COX-2 and the VEGF ovarian levels. The effect of metformin in preventing the increase in ovarian COX-2 expression has also been 
observed in an animal model of PCOS [19]. Moreover, the effect of metformin in decreasing VEGF levels has been also described in other systems [51,52]. Taking into account these findings, we suggest that, in our model, metformin was able to normalize vascular permeability by normalizing the VEGF abundance and may be acting through COX-2 and NOS. An important regulator of these angiogenic molecules is hypoxia-inducible factor-1 (HIF-1). This transcriptional complex is expressed in rat ovarian granulosa cells in response to hCG treatment, and the inhibition of HIF-1 inhibits ovulation in rats [53]. HIF-1 increases the transcription of several genes to produce proteins that promote blood flow and inflammation including VEGF, NOS and COX-2 [54].

Further studies are being designed to clarify whether metformin normalizes vascular capillarity directly by affecting ovarian COX-2 and VEGF abundance or if metformin only decreases ovarian COX-2 levels, whether this protein normalizes vascular capillarity by regulating VEGF levels, and to elucidate whether HIF-1 is involved in this interplay.

In conclusion, our results demonstrate that metformin has a beneficial effect on OHSS by reducing increasing body weight, circulating progesterone and estradiol and vascular permeability. These effects are mediated by a metformin-mediated inhibition of the vasoactive molecules VEGF, COX-2 and partially NOS, which are molecules increased in OHSS and responsible for a variety of symptoms related to OHSS.

\section{Competing interests}

The authors declared that they have no competing interest.

\section{Authors' contributions}

$E M E, R Q, D A P$ and $C P$ were responsible for the conceptualization of the work, data interpretation and manuscript preparation. EME, RQ, CC VB and GRV assisted in data collection and all the experiments. DAP and CP designed and supervised the study. All authors read and approved the final manuscript.

\section{Acknowledgements}

The author thanks Lucas Jungblut for the assistance in the statistics.

\section{Author details}

'Laboratorio de Biología del Desarrollo, Facultad de Ciencias Exactas y Naturales, Instituto de Fisiología, Biología Molecular y Neurociencias (IFIBYNE-CONICET-UBA), Pabellón 2, 4 C1428EHA Cdad Universitaria, Buenos Aires, Argentina. ${ }^{2}$ Procrearte, Medicina Reproductiva y Molecular, Buenos Aires, Argentina. ${ }^{3}$ Departamento de Biodiversidad y Biología Experimental, Facultad de Ciencias Exactas y Naturales, Universidad de Buenos Aires, Pabellón 2, Cdad, Universitaria, Buenos Aires, Argentina. ${ }^{4}$ Departamento de Morfología, Escuela de Ciencias Básicas, Facultad de Salud, Universidad del Valle, Cali, Colombia.

Received: 1 June 2013 Accepted: 31 August 2013 Published: 8 September 2013

\section{References}

1. Albert C, Garrido N, Mercader A, Rao CV, Remohí J, et al: The role of endothelial cells in the pathogenesis of ovarian hyperstimulation syndrome. Mol Hum Reprod 2002, 8(5):409-418.
2. Friedman Cl, Danforth DR, Herbosa-Encarnacion C, Arbogast L, Alak BM, et al: Follicular fluid vascular endothelial growth factor concentrations are elevated in women of advanced reproductive age undergoing ovulation induction. Fertil Steril 1997, 68(4):607-612.

3. Manau D, Fábregues F, Peñarrubia J, Creus M, Carmona F, et al: Vascular endothelial growth factor levels in serum and plasma from patients undergoing controlled ovarian hyperstimulation for IVF. Hum Reprod 2007, 22(3):669-675.

4. Quintana R, Kopcow L, Marconi G, Young E, Yovanovich C, et al: Inhibition of cyclooxygenase-2 (COX-2) by meloxicam decreases the incidence of ovarian hyperstimulation syndrome in a rat model. Fertil Steril 2008, 90(4, Supplement):1511-1516.

5. Gomez R, Soares SR, Busso C, Garcia-Velasco JA, Simon C, et al: Physiology and pathology of ovarian hyperstimulation syndrome. Semin Reprod Med 2010, 28(6):448-457.

6. Gomez R, Ferrero H, Delgado-Rosas F, Gaytan M, Morales C, et al: Evidences for the existence of a low dopaminergic tone in polycystic ovarian syndrome: implications for OHSS development and treatment. J Clin Endocrinol Metab 2011, 96(8):2484-2492.

7. Fujii E, Irie K, Ohba K, Ogawa A, Yoshioka T, et al: Role of nitric oxide, prostaglandins and tyrosine kinase in vascular endothelial growth factorinduced increase in vascular permeability in mouse skin. Naunyn Schmiedebergs Arch Pharmacol 1997, 356(4):475-480.

8. Hester KE, Harper MJK, Duffy DM: Oral administration of the cyclooxygenase-2 (COX-2) inhibitor meloxicam blocks ovulation in non-human primates when administered to simulate emergency contraception. Hum Reprod 2010, 25(2):360-367.

9. Jesam C, Salvatierra AM, Schwartz JL, Croxatto HB: Suppression of follicular rupture with meloxicam, a cyclooxygenase-2 inhibitor: potential for emergency contraception. Hum Reprod 2010, 25(2):368-373.

10. Zhou G, Myers R, Li Y, Chen Y, Shen X, et al: Role of AMP-activated protein kinase in mechanism of metformin action. J Clin Invest 2001, 108(8):1167-1174.

11. Fryer LGD, Parbu-Patel A, Carling D: The anti-diabetic drugs rosiglitazone and metformin stimulate AMP-activated protein Kinase through distinct signaling pathways. J Biol Chem 2002, 277(28):25226-25232.

12. Zou M-H, Kirkpatrick SS, Davis BJ, Nelson JS, Wiles WG, et al: Activation of the AMP-activated Protein Kinase by the Anti-diabetic Drug Metformin in Vivo. J Biol Chem 2004, 279(42):43940-43951.

13. Viollet B, Guigas B, Sanz Garcia N, Leclerc J, Foretz M, et al: Cellular and molecular mechanisms of metformin: an overview. Clin Sci (Lond) 2011, 122(6):253-270.

14. Morin-Papunen L, Rantala AS, Unkila-Kallio L, Tiitinen A, Hippelainen M, et al: Metformin improves pregnancy and live-birth rates in women with polycystic ovary syndrome (PCOS): a multicenter, double-blind, placebocontrolled randomized trial. J Clin Endocrinol Metab 2012, 97(5):1492-1500.

15. Elia EM, Pustovrh C, Amalfi S, Devoto L, Motta AB: Link between metformin and the peroxisome proliferator-activated receptor $\gamma$ pathway in the uterine tissue of hyperandrogenized prepubertal mice. Fertil Steril 2011, 95(8):2534-2537. e1.

16. Ghazeeri GS, Nassar AH, Younes Z, Awwad JT: Pregnancy outcomes and the effect of metformin treatment in women with polycystic ovary syndrome: an overview. Acta Obstet Gynecol Scand 2012, 91(6):658-678.

17. Xiao J, Chen S, Zhang C, Chang S: The effectiveness of metformin ovulation induction treatment in patients with PCOS: a systematic review and meta-analysis. Gynecol Endocrinol 2012.

18. Wei Z, Cao Y, Cong L, Zhou P, Zhang Z, et al: Effect of metformin pretreatment on pregnancy outcome of in vitro matured oocytes retrieved from women with polycystic ovary syndrome. Fertil Steril 2008, 90(4):1149-1154.

19. Elia E, Sander V, Luchetti CG, Solano ME, Di Girolamo G, et al: The mechanisms involved in the action of metformin in regulating ovarian function in hyperandrogenized mice. Mol Hum Reprod 2006, 12(8):475-481.

20. Elia EM, Belgorosky D, Faut M, Vighi S, Pustovrh C, et al: The effects of metformin on uterine tissue of hyperandrogenized $B A L B / c$ mice. Mol Hum Reprod 2009, 15(7):421-432.

21. Solano ME, Elia E, Luchetti CG, Sander V, Di Girolamo G, et al: Metformin prevents embryonic resorption induced by hyperandrogenisation with dehydroepiandrosterone in mice. Reprod Fertil Dev 2006, 18(5):533-544.

22. Palomba S, Falbo A, Carrillo L, Villani MT, Orio F, et al: Metformin reduces risk of ovarian hyperstimulation syndrome in patients with polycystic 
ovary syndrome during gonadotropin-stimulated in vitro fertilization cycles: a randomized, controlled trial. Fertil Steril 2011, 96(6):1384-1390. e4.

23. Ujioka T, Matsuura K, Kawano T, Okamura H: Role of progesterone in capillary permeability in hyperstimulated rats. Hum Reprod 1997, 12(8):1629-1634

24. Saylan A, Arioz DT, Koken T, Dilek H, Saylan F, et al: Prevention of ovarian hyperstimulation syndrome in a rat model: efficacy comparison between cabergoline and meloxicam. Acta Obstet Gynecol Scand 2010, 89(5):692-699. doi:10.3109/00016341003592537.

25. Scotti L, Abramovich D, Pascuali N, de Zuniga I, Oubina A, et al: Involvement of the ANGPTs/Tie-2 system in ovarian hyperstimulation syndrome (OHSS). Mol Cell Endocrinol 2012, 365(2):223-230.

26. Scotti L, Irusta G, Abramovich D, Tesone M, Parborell F: Administration of a gonadotropin-releasing hormone agonist affects corpus luteum vascular stability and development and induces luteal apoptosis in a rat model of ovarian hyperstimulation syndrome. Mol Cell Endocrinol 2011, 335(2):116-125.

27. Kitajima Y, Endo T, Nagasawa K, Manase K, Honnma H, et al: Hyperstimulation and a gonadotropin-releasing hormone agonist modulate ovarian vascular permeability by altering expression of the tight junction protein claudin-5. Endocrinology 2006, 147(2):694-699. Epub 2005 Nov 3.

28. Woodruff TK, D'Agostino J, Schwartz NB, Mayo KE: Dynamic changes in inhibin messenger RNAs in rat ovarian follicles during the reproductive cycle. Science 1988, 239(4845):1296-1299.

29. Cheng G, Weihua Z, Mäkinen S, Mäkelä S, Saji S, et al: A role for the androgen receptor in follicular atresia of estrogen receptor beta knockout mouse ovary. Biol Reprod 2002, 66(1):77-84.

30. Hu Y-C, Wang P-H, Yeh S, Wang R-S, Xie C, et al: Subfertility and defective folliculogenesis in female mice lacking androgen receptor. Proc Natl Acad Sci USA 2004, 101(31):11209-11214.

31. D'Angelo A, Amso N: Embryo freezing for preventing ovarian hyperstimulation syndrome. Cochrane Database Syst Rev 2007, 3:CD002806

32. Isikoglu M, Berkkanoglu M, Senturk Z, Ozgur K: Human albumin does not prevent ovarian hyperstimulation syndrome in assisted reproductive technology program: a prospective randomized placebo-controlled double blind study. Fertil Steril 2007, 88(4):982-985. Epub 2007 Feb 20.

33. Engmann L, DiLuigi A, Schmidt D, Nulsen J, Maier D, et al: The use of gonadotropin-releasing hormone $(\mathrm{GnRH})$ agonist to induce oocyte maturation after cotreatment with $\mathrm{GnRH}$ antagonist in high-risk patients undergoing in vitro fertilization prevents the risk of ovarian hyperstimulation syndrome: a prospective randomized controlled study. Fertil Steril 2008, 89(1):84-91. Epub 2007 Apr 26.

34. Busso C, Fernandez-Sanchez M, Garcia-Velasco JA, Landeras J, Ballesteros A et al: The non-ergot derived dopamine agonist quinagolide in prevention of early ovarian hyperstimulation syndrome in IVF patients: a randomized, double-blind, placebo-controlled trial. Hum Reprod 2010, 25(4):995-1004. doi:10.1093/humrep/deq005. Epub 2010 Feb 6.

35. Lainas TG, Sfontouris IA, Zorzovilis IZ, Petsas GK, Lainas GT, et al: Flexible $\mathrm{GnRH}$ antagonist protocol versus $\mathrm{GnRH}$ agonist long protocol in patients with polycystic ovary syndrome treated for IVF: a prospective randomised controlled trial (RCT). Hum Reprod 2010, 25(3):683-689. doi:10.1093/humrep/dep436. Epub 2009 Dec 15

36. Varnagy A, Bodis J, Manfai Z, Wilhelm F, Busznyak C, et al: Low-dose aspirin therapy to prevent ovarian hyperstimulation syndrome. Fertil Steril 2010, 93(7):2281-2284. doi:10.1016/j.fertnstert.2009.01.085. Epub 2009 Mar 3.

37. Tang T, Glanville J, Orsi N, Barth JH, Balen AH: The use of metformin for women with PCOS undergoing IVF treatment. Hum Reprod 2006, 21(6):1416-25. Epub 2006 Feb 24

38. Palomba S, Falbo A, Orio F Jr, Manguso F, Russo T, et al: A randomized controlled trial evaluating metformin pre-treatment and co-administration in non-obese insulin-resistant women with polycystic ovary syndrome treated with controlled ovarian stimulation plus timed intercourse or intrauterine insemination. Hum Reprod 2005, 20(10):2879-2886. Epub 2005 Jun 15.

39. Meldrum DR, Chang RJ, De-Ziegler D, Schoolcraft WB, Scott RT Jr, et al: Adjuncts for ovarian stimulation: when do we adopt "orphan indications" for approved drugs? Fertil Steril 2009, 92(1):13-18. doi:10.1016/j.fertnstert. 2009.03.081. Epub 2009 May 6.

40. Palomba S, Falbo A, La-Sala GB: Effects of metformin in women with polycystic ovary syndrome treated with gonadotrophins for in vitro fertilisation and intracytoplasmic sperm injection cycles: a systematic review and metaanalysis of randomised controlled trials. BJOG 2013, 120(3):267-276.

41. De Leo V, la Marca A, Ditto A, Morgante G, Cianci A: Effects of metformin on gonadotropin-induced ovulation in women with polycystic ovary syndrome. Fertil Steril 1999, 72(2):282-285

42. Gomez R, Simon C, Remohi J, Pellicer A: Administration of moderate and high doses of gonadotropins to female rats increases ovarian vascular endothelial growth factor (VEGF) and VEGF receptor-2 expression that is associated to vascular hyperpermeability. Biol Reprod 2003, 68(6):2164-2171.

43. Ozcakir HT, Giray SG, Ozbilgin MK, Inceboz US, Caglar H: Effect of angiotensin-converting enzyme-inhibiting therapy on the expression of vascular endothelial growth factor in hyperstimulated rat ovary. Fertil Steril 2004, 82(Suppl 3):1127-1132.

44. Lee A, Christenson LK, Stouffer RL, Burry KA, Patton PE: Vascular endothelial growth factor levels in serum and follicular fluid of patients undergoing in vitro fertilization. Fertil Steril 1997, 68(2):305-311.

45. Haghighi Poodeh S, Salonurmi T, Nagy I, Koivunen P, Vuoristo J, et al: Alcohol-induced premature permeability in mouse placenta-yolk sac barriers in vivo. Placenta 2012, 10:866-873.

46. Sun Z, Li X, Massena S, Kutschera S, Padhan N, et al: VEGFR2 induces c-Src signaling and vascular permeability in vivo via the adaptor protein TSAd. J Exp Med 2012, 209(7):1363-1377.

47. Solskov L, Lofgren B, Kristiansen SB, Jessen N, Pold R, et al: Metformin induces cardioprotection against ischaemia/reperfusion injury in the rat heart 24 hours after administration. Basic Clin Pharmacol Toxicol 2008, 103(1):82-87.

48. Cianchi F, Cortesini C, Fantappie O, Messerini L, Sardi I, et al: Cyclooxygenase- 2 activation mediates the proangiogenic effect of nitric oxide in colorectal cancer. Clin Cancer Res 2004, 10(8):2694-2704.

49. Wu AW, Gu J, Li ZF, Ji JF, Xu GW: COX-2 expression and tumor angiogenesis in colorectal cancer. World J Gastroenterol 2004, 10(16):2323-2326.

50. Toomey DP, Murphy JF, Conlon KC: COX-2, VEGF and tumour angiogenesis. Surgeon 2009, 7(3):174-180

51. Rattan R, Graham RP, Maguire JL, Giri S, Shridhar V: Metformin suppresses ovarian cancer growth and metastasis with enhancement of cisplatin cytotoxicity in vivo. Neoplasia 2011, 13(5):483-491.

52. Ersoy C, Kiyici S, Budak F, Oral B, Guclu M, et al: The effect of metformin treatment on VEGF and PAI-1 levels in obese type 2 diabetic patients. Diabetes Res Clin Pract 2008, 81(1):56-60. doi:10.1016/j.diabres.2008.02.006. Epub 2008 Mar 21

53. Zhang J, Zhang Z, Wu Y, Chen L, Luo Q, et al: Regulatory effect of hypoxia-inducible factor-1alpha on hCG-stimulated endothelin-2 expression in granulosa cells from the PMSG-treated rat ovary. J Reprod Dev 2012, 58(6):678-684. Epub 2012 Aug 20.

54. Hellwig-Burgel T, Stiehl DP, Wagner AE, Metzen E, Jelkmann W: Review: hypoxia-inducible factor-1 (HIF-1): a novel transcription factor in immune reactions. J Interferon Cytokine Res 2005, 25(6):297-310.

doi:10.1186/1757-2215-6-62

Cite this article as: Elia et al:: Metformin decreases the incidence of ovarian hyperstimulation syndrome: an experimental study. Journal of Ovarian Research 2013 6:62.

\section{Submit your next manuscript to BioMed Central and take full advantage of:}

- Convenient online submission

- Thorough peer review

- No space constraints or color figure charges

- Immediate publication on acceptance

- Inclusion in PubMed, CAS, Scopus and Google Scholar

- Research which is freely available for redistribution 